\title{
Genotypic Variation in Trichomonas vaginalis Detected in South African Pregnant Women
}

\author{
Rennisha Chetty (D), Nonkululeko Mabaso $(\mathbb{D}$, and Nathlee Abbai $(\mathbb{C}$ \\ School of Clinical Medicine Laboratory, College of Health Sciences, University of KwaZulu-Natal, South Africa \\ Correspondence should be addressed to Nathlee Abbai; abbain@ukzn.ac.za
}

Received 7 April 2020; Revised 25 June 2020; Accepted 14 July 2020; Published 5 August 2020

Academic Editor: Bryan Larsen

Copyright (c) 2020 Rennisha Chetty et al. This is an open access article distributed under the Creative Commons Attribution License, which permits unrestricted use, distribution, and reproduction in any medium, provided the original work is properly cited.

\begin{abstract}
Background. Trichomonas vaginalis is the causative agent of trichomoniasis. The genetic characterisation of T. vaginalis isolates reveals significant genetic diversity in this organism. Data on the prevalence of different genotypes of T. vaginalis in South African populations is lacking. This study investigated the diversity of T. vaginalis in a pregnant population in South Africa. Methods. In this study, 362 pregnant women from the King Edward VIII Hospital in Durban, South Africa, provided vaginal swabs to be tested for the presence of $T$. vaginalis. T. vaginalis was detected using the TaqMan assay using commercially available primers and probes specific for this protozoan (Pr04646256_s1). The actin gene from T. vaginalis was amplified with gene-specific primers. The actin amplicons were digested with HindII, MseI, and RsaI, and the banding patterns were compared across the three digests for assignment of genotypes. Phylogenetic analysis was conducted using MEGA. Results. The prevalence of $T$. vaginalis in the study population was $12.9 \%$ (47/362). Genotype $G$ was the most frequent genotype in our study population. Genotypes H and I were detected in one sample each. According to the multiple sequence alignments and phylogenetic analysis, a level of diversity was observed across and within genotypes. Four different single-nucleotide changes in the actin gene were detected. Sample TV358 (H genotype) contained a single amino acid substitution from glutamine to lysine. Sample TV184 (G genotype) contained a single amino acid substitution from glutamic acid to arginine. Sample TV357 (G genotype) contained two amino acid substitutions, arginine to leucine and glycine to aspartic acid. Conclusion. Three different genotypes were observed in the pregnant population. Diversity was observed across and within genotypes. The observed diversity can be challenging for future vaccine design and development of antigen-based rapid diagnostic tests for trichomoniasis.
\end{abstract}

\section{Introduction}

Trichomonas vaginalis is referred to as an anaerobic, flagellated protozoan and the causative agent of trichomoniasis. This particular parasite can be transmitted via sexual intercourse from host to host [1]. Trichomoniasis is considered to be the most prevalent nonviral sexually transmitted infection (STI) worldwide affecting individuals of all ages, ethnicity, and socioeconomic groups [1-4]. The World Health Organization (WHO) estimated that in the year 2012, approximately 143 million new cases of trichomoniasis were reported in adults aged between 15 and 49 years [5]. T. vaginalis can infect both males and females; however, the infection rate is much higher in women [6].
Trichomoniasis has been reported to have over 276.4 million reported infections worldwide [7]. Out of the 276 million cases, 25 million cases have been reported in pregnant women [8]. Pregnant women infected with $T$. vaginalis have a higher risk of preterm delivery since $T$. vaginalis causes the premature rupture of membranes. A previous study has shown that pregnant women infected with $T$. vaginalis have a $30 \%$ risk of preterm delivery or delivering infants who have a low birth weight [9]. T. vaginalis infection also contributes to the increase in mother-to-child transmission of HIV [10].

Many molecular-based techniques have been used in the past in order to distinguish $T$. vaginalis strains by techniques which include microsatellite genotyping, multilocus sequence typing (MLST), polymerase chain reaction- 
TABLE 1: Description of primers used for the amplification of the actin genes in the studied population.

\begin{tabular}{lc}
\hline Primer name & Primer sequence \\
\hline Outer actin forward (Tv8S) & $5^{\prime}$-TCTGGAATGGCTGAAGAAGACG-3' \\
Outer actin reverse (Tv9R) & $5^{\prime}$-CAGGGTACATCGTATTGGTC-3' \\
Inner actin forward (Tv10S) & $5^{\prime}$-CAGACACTCGTTATCG-3' \\
Inner actin reverse (Tv11R) & $5^{\prime}$-CGGTGAACGATGGATG-3' \\
\hline
\end{tabular}

(PCR-) hybridization, random amplification of polymorphic DNA (RAPD), and PCR-size polymorphism as well as PCRrestriction fragment length polymorphism (PCR-RFLP) [6]. Actin is one of the structural proteins present in T. vaginalis. This protein is well-conserved and ubiquitous in nature, thereby making it a likely option for intraspecies molecular identification [11]. To validate the use of this protein for the genetic characterisation of $T$. vaginalis, Crucitti et al. [12] conducted a study using PCR-RFLP, to identify different genotypes of T. vaginalis based on the actin gene. The study identified eight $T$. vaginalis actin genotypes among 151 isolates obtained from the Democratic Republic of Congo and Zambia [12].

The genetic characterisation of $T$. vaginalis isolates showed that there is significant genetic diversity in this organism [11]. Currently, there is a lack of data on the circulating genotypes of T. vaginalis in South African populations, particularly pregnant women. In this study, PCR-RFLP of the actin gene was performed in order to identify the different genotypes circulating in our population. Identification of the genotypes will provide a snapshot into the molecular epidemiology of $T$. vaginalis in our region which can be used as a foundation for larger epidemiological studies on this pathogen.

\section{Methodology}

2.1. Ethics Statement. The current study was approved by the Biomedical Research Ethics Committee (BREC) of the University of KwaZulu-Natal (BREC/00000406/2019).

2.2. Study Population. The study was conducted in $n=362$ pregnant women from the antenatal clinic of the King Edward VIII Hospital in Durban, South Africa. The study was conducted from October 2018 to April 2019. Women presenting with and without symptoms of abnormal vaginal discharge were part of the study. Women presenting with symptoms were treated as part of the standard of care which was the syndromic approach for vaginal discharge syndrome. The enrolled women provided self-collected vaginal swabs for the detection of T. vaginalis.

2.3. DNA Extraction from Vaginal Swabs. Upon collection, the vaginal swab was placed in a sterile tube for molecular analysis. The samples were transported at room temperature to the School of Clinical Medicine's Research Laboratory at the Nelson R. Mandela School of Medicine, University of KwaZulu-Natal. The swabs were then resuspended in $2 \mathrm{ml}$ of phosphate-buffered saline (PBS) and vortexed to remove the sample material from the swab. After vortexing, the swab was discarded and the PBS solution containing the vaginal material was subjected to DNA extraction. For the extraction, the entire $2 \mathrm{ml}$ of PBS was used and the DNA was extracted using the PureLink Microbiome DNA Purification Kit (Invitrogen, supplied by ThermoFisher Scientific, United States) according to the manufacturer's instructions. The concentration and purity of the extracted DNA was assessed using the NanoDrop spectrophotometer (ThermoFisher Scientific, United States).

2.4. Detection of T. vaginalis from DNA Extracted from Vaginal Swabs. A total of $n=362$ vaginal swab DNA samples were tested for the presence of $T$. vaginalis. T. vaginalis was detected using the Applied Biosystems ${ }^{\mathrm{TM}}{ }^{\text {TaqMan }}{ }^{\circledR}$ Assays. Commercial primers and probes (Pr04646256_s1) which target the alpha tubulin 1 gene of T. vaginalis were used. Amplification was performed on the QuantStudio 5 Real-Time PCR Detection System (ThermoFisher Scientific, USA). Briefly, each reaction was performed in a final volume of $5 \mu \mathrm{l}$ that comprised $0.5 \mu \mathrm{l}$ FAM-labelled probe/primer mix for individual targets, $2.5 \mu \mathrm{l}$ FastStart $4 \mathrm{x}$ probe master mix (ThermoFisher Scientific, Pr04646256_s1), $1.5 \mu \mathrm{L}$ template DNA, and nuclease-free water. We also included nontemplate control reactions. Amplification was performed under the following conditions: 1 cycle at $95^{\circ} \mathrm{C}$ for 30 seconds followed by 45 cycles of denaturation at $95^{\circ} \mathrm{C}$ for 3 seconds and annealing at $60^{\circ} \mathrm{C}$ for 30 seconds. The detection of fluorescent products was performed at the end of the annealing period. The raw fluorescent data that included the $C_{\mathrm{T}}$ mean values were automatically generated by the QuantStudio 5 Real-Time PCR System software.

2.5. Detection of the Actin Genes from T. vaginalis. A conventional nested PCR assay was used for the amplification of the actin genes (outer and inner regions) using oligonucleotide primers, published by Espinosa et al. [13] and Khalili et al. [6]. The primers used for amplification of inner and outer actin genes in one woman are shown in Table 1.

2.6. Amplification of the Outer Actin Gene. The amplification reactions were performed in PCR with a total volume of $25 \mu \mathrm{l}$. The reaction contained $12.5 \mu \mathrm{l}$ DreamTaq master mix (ThermoFisher Scientific, Massachusetts, United States), $9.5 \mu \mathrm{l}$ distilled water, and $0.5 \mu l$ of each primer (reverse and forward), and $2 \mu \mathrm{l}$ of no-template PCR product was used. The negative control contained $23 \mu \mathrm{l}$ of PCR mixture and $2 \mu \mathrm{l}$ of distilled water. Thereafter, the PCR tubes were placed into the thermal cycler and the following conditions were 
performed, for gene amplification, initial denaturation at $94^{\circ} \mathrm{C}$ for 5 minutes, thereafter 30 cycles: denaturation at $94^{\circ} \mathrm{C}$ for 1 minute, annealing $54^{\circ} \mathrm{C}$ for 1 minute, elongation $72^{\circ} \mathrm{C}$ for 1 minute, and final elongation at $72^{\circ} \mathrm{C}$ for 5 minutes.

2.7. Amplification of the Inner Actin Gene by Nested PCR. The nested amplification reactions were performed in PCR with a total volume of $25 \mu \mathrm{l}$. The reaction contained $12.5 \mu \mathrm{l}$ DreamTaq master mix, $9.5 \mu \mathrm{l}$ distilled water, $0.5 \mu \mathrm{l}$ of each primer (reverse and forward) and $2 \mu \mathrm{l}$ of outer PCR product. The negative control contained $23 \mu \mathrm{l}$ of PCR mixture and $2 \mu \mathrm{l}$ of distilled water. Thereafter, the PCR tubes were placed into the thermal cycler and the following conditions were performed: for gene amplification, initial denaturation at $94^{\circ} \mathrm{C}$ for 5 minutes, thereafter 30 cycles: denaturation at $94^{\circ} \mathrm{C}$ for 1 minute, annealing $45^{\circ} \mathrm{C}$ for 1 minute, elongation $72^{\circ} \mathrm{C}$ for 1 minute, and final elongation at $72^{\circ} \mathrm{C}$ for 5 minutes.

2.8. Sequence Confirmation of the Actin Gene. A subset of PCR positive amplicons was sequenced to confirm the presence of the gene prior to the genotyping analysis. Sanger DNA sequencing was performed on the inner actin PCR amplicons. Each amplicon was sequenced in both directions to cover the full-length actin gene. The sequencing was conducted using the BrilliantDye ${ }^{\mathrm{TM}}$ Terminator v3.1 Cycle Sequencing on an ABI3500XL genetic analyser. The sequencing was performed at Inqaba Biotechnical Industries (Hatfield, Pretoria, South Africa). The ABI sequencing files were edited on CHROMAS (Technelysium, Queensland, Australia). The forward and reverse sequences were aligned using the DNAMAN software (Lynnon Biosoft, California, United States). The identity of the edited sequences was confirmed using the National Center for Biotechnology Information (NCBI) Basic Local Alignment Search Tool (BLAST).

2.9. Restriction Fragment Length Polymorphisms (RFLP). The genotyping of the actin genes was performed using the RFLP technique. Restriction enzymes, HindII, MseI, and RsaI were used to generate banding profiles. The inner actin amplicons were digested with the individual enzymes. The digestion mix was made up to a final volume of $20 \mu \mathrm{l}$. Each reaction consisted of $0.5 \mu \mathrm{l}$ enzyme, $2 \mu \mathrm{l}$ enzyme buffer, $0.2 \mu \mathrm{l}$ bovine serum albumin (BSA), $7.3 \mu \mathrm{l}$ distilled water, and $10 \mu \mathrm{l}$ of the PCR amplicon. The digestion reactions were incubated for 4 hours under the following temperature conditions: $37^{\circ} \mathrm{C}$ for both MseI and RsaI enzymes and $64^{\circ} \mathrm{C}$ for the HindII restriction enzyme [6]. Following incubation, the digests were run on a $2 \%$ agarose gel which were stained with $4 \mu \mathrm{l}$ of SYBR Safe dye (ThermoFisher Scientific, Massachusetts, United States). Each well was then loaded with $5 \mu$ l of loading dye and $20 \mu \mathrm{l}$ of the digestion mix. The gels were electrophoresed at $80 \mathrm{~V}$ for 2 hours. The enzyme's banding patterns and assignment of genotypes based on a composite of the patterns were determined according to Khalili et al. [6].

2.10. Phylogenetic Analysis of Actin Genotypes. Selected samples harbouring different genotypes for the actin gene after digestion with the 3 enzymes were selected for further phylogenetic analysis. The amplicons were sequenced in both directions using the Sanger approach. The sequencing was performed on an ABI3500XL genetic analyser at Inqaba Biotechnical Industries (Hatfield, Pretoria, South Africa). The ABI sequencing files were edited on CHROMAS (Technelysium, Queensland, Australia). The forward and reverse sequences were aligned using the DNAMAN software (Lynnon Biosoft, California, United States). The DNA sequences were translated to protein using the freely available software ExPASy (https://web.expasy.org/translate/). The translated sequences together with published actin protein sequences were aligned using ClustalW (https://www.genome.jp/toolsbin/clustalw). The alignments were performed in order to identify amino acid substitutions. A phylogenetic tree was then constructed from the sequence data using the Molecular Evolutionary Genetics Analysis (MEGA) version 10 software (Arizona, United States).

\section{Results}

3.1. Detection of $T$. vaginalis from DNA Extracted from Vaginal Swabs. The presence of the alpha tubulin 1 gene was detected in $47 / 362$ swab DNA samples by the real-time PCR TaqMan assay. The prevalence of $T$. vaginalis in this population was 12.98 . The quantification cycle $\left(C_{\mathrm{q}}\right)$ for the samples that produced positive amplification ranged from 25 to 35 cycles. All negative no-template controls did not produce any amplification.

3.2. Amplification of the Outer and Inner Actin Genes of T. vaginalis. Amplification of the outer actin gene by conventional PCR yielded 16 positives out of the 47 samples tested. The majority of the samples (23/31) that did not test positive in the initial PCR showed either low DNA concentration or purity ratios. For the low-concentration samples, the reactions were repeated with an increased amount of DNA; however, the adjustment still did not result in successful amplification of the outer actin gene. The inner actin gene was amplified from all 16 samples. The expected fragment size of $1100 \mathrm{bp}$ was observed by agarose gel electrophoresis (Figure 1). The DNA sequencing hits of the actin gene showed identity (99\%) to T. vaginalis isolate 19 actin gene (MF350343.1) and T. vaginalis strain ATCC 30240 actin gene (99\%) (EU076579.1).

\subsection{Genotyping Analysis}

3.3.1. HindII Profile. All samples produced a banding pattern for HindII. A similar banding profile was observed across all samples (Figure 2). Numerous bands were observed for this digest which had not been previously published [6]. Since all the samples produced the same banding profile, an in silico analysis was performed on nine samples for which the full sequences of the actin gene were available using the freely available Restriction Mapper tool (http://www .restrictionmapper.org/cgi-bin/sitefind3.pl). The in silico data for one sample (TV266) is shown in Table 2. According to Restriction Mapper, only four fragments should have been yielded at positions $60 \mathrm{bp}, 200 \mathrm{bp}, 386 \mathrm{bp}$, and $426 \mathrm{bp}$ (Table 2). These four fragments were shown to be present on the gel (Figure 2). The additional bands observed could have been due to star activity by the enzyme (i.e., cutting at 

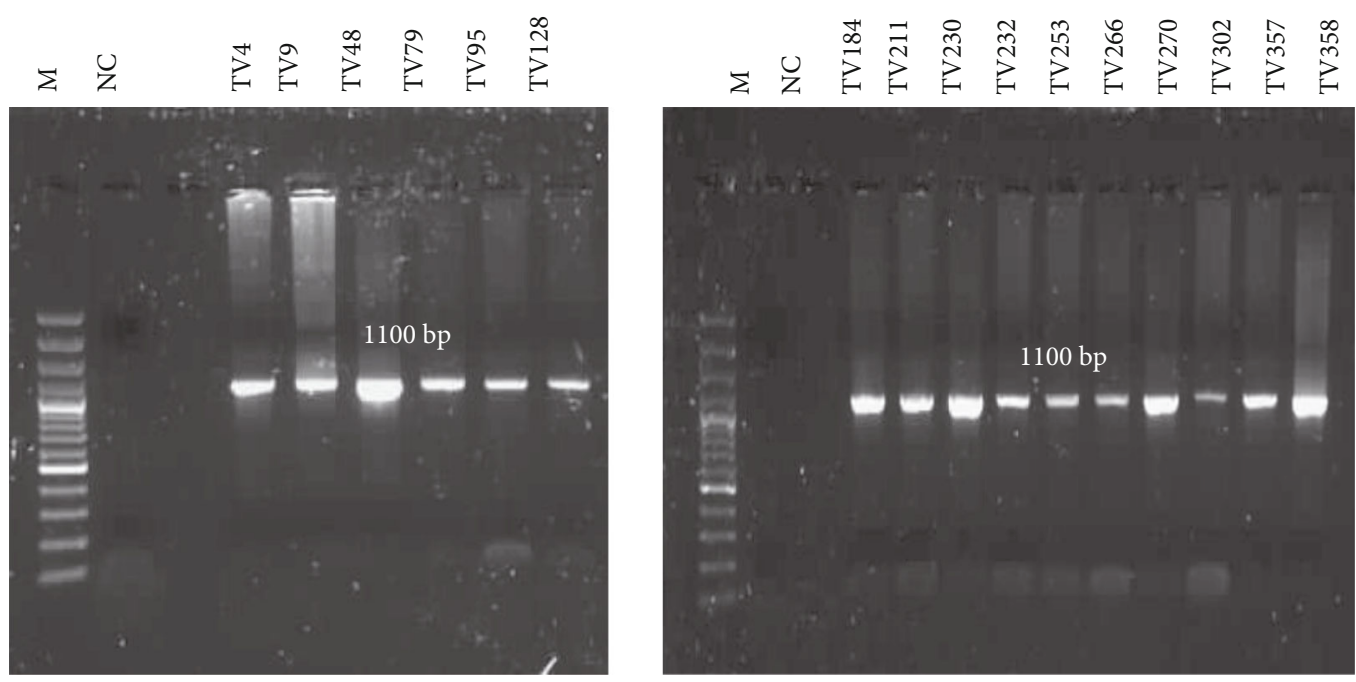

FIgURE 1: Agarose gel showing positive amplicons generated for the inner actin gene. The expected fragment size of $1100 \mathrm{bp}$ was observed. M: 100 bp DNA molecular ladder (ThermoFisher Scientific), NC: negative control (no template DNA added), and amplified clinical samples. A product size of $1100 \mathrm{bp}$ indicative of the inner actin gene was present in all 16 samples tested.
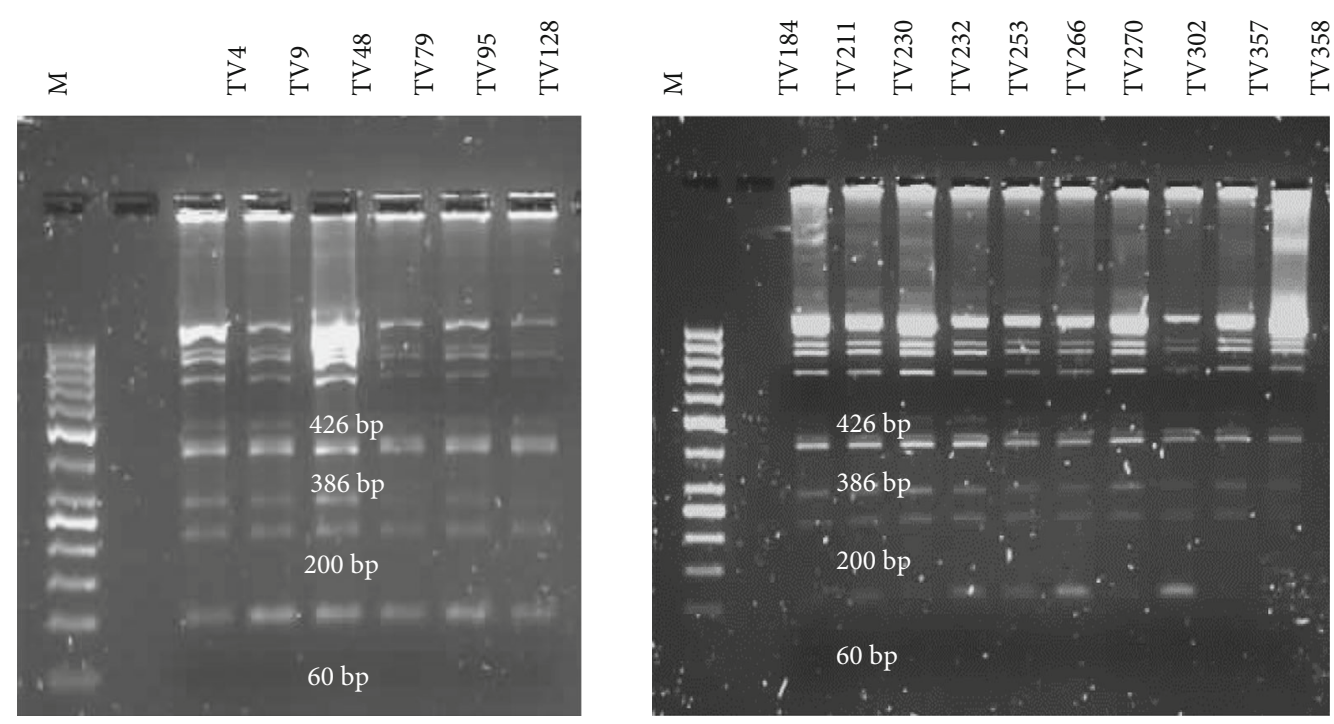

Figure 2: HindII RFLP pattern of the digested actin gene amplicon resolved on a $1.5 \%$ agarose gel. M: O'GeneRuler 50 bp DNA Ladder (ThermoFisher Scientific) and banding profiles of the clinical samples. Size fragments of $60 \mathrm{bp}, 200 \mathrm{bp}, 386 \mathrm{bp}$, and $426 \mathrm{bp}$ were observed for the respective samples.

nonspecific recognition sites due to prolonged incubation period or too high enzyme concentration). Based on the identical banding pattern across all samples, the samples were assigned the same pattern code, i.e., pattern 2 (Table 3). The in silico analysis that was performed on the nine samples did not alter the assignment of the genotypes; it confirmed the genotype assignments based on the HindII digests.

3.3.2. RsaI Profile. All samples produced banding patterns for RsaI. Three different banding patterns were observed for RsaI (Figure 3). Of the 16 samples digested, 13/16 (81.25\%) of the samples produced four fragment sizes at positions $106 \mathrm{bp}$, $190 \mathrm{bp}, 236 \mathrm{bp}$, and $568 \mathrm{bp}$. This group of samples were assigned the code pattern 1. Two of the 16 samples $(12.50 \%)$ produced three fragment sizes at positions $106 \mathrm{bp}$, ${ }^{2} 36 \mathrm{bp}$, and $568 \mathrm{bp}$, and the one sample $(6.25 \%)$ produced four fragments at positions $106 \mathrm{bp}, 190 \mathrm{bp}, 236 \mathrm{bp}$, and $452 \mathrm{bp}$. The groups were assigned the codes patterns 2 and 3 , respectively (Table 3 ). The size of the digestion fragments obtained corresponded to previous studies that reported on genotyping of the actin gene by RsaI digestion.

3.3.3. MseI Profile. For the MseI reactions, one sample did not produce a banding pattern despite numerous adjustments such as increased incubation time and increased amounts of template DNA. The sample produced a very faint uncut band. For the remaining 15/16 (93.75\%) of the samples, an 
TABLE 2: Virtual digest of sample TV266 with the Restriction Mapper tool (http://www.restrictionmapper.org/cgi-bin/sitefind3.pl).

\begin{tabular}{|c|c|c|c|c|c|}
\hline Length & $5^{\prime}$ enzyme & $5^{\prime}$ base & $3^{\prime}$ enzyme & $3^{\prime}$ base & Sequence \\
\hline 426 & HindII & 261 & HindII & 686 & $\begin{array}{l}\text { GACCCAACAG AGCACCCAGT TCTTCTTACA GAAGCCCCAC TCAACCCAAAG } \\
\text { GCTAACCGT GAGAAAATGA TCTCCCTCAT GTTCGACACATTCAATGTCCC } \\
\text { ATCCTTCTA TGTCGGCATC CAGGCTGTTCTTTCCCTCTA CTCCTCTGGCC } \\
\text { GTACAACAGGTATCGTTTT CGATGCTGGT GATGGTGTTT CCCACACAGTT } \\
\text { CCAATTTAC GAAGGCTACT CCCTTCCACA CGCCATCATG AGACTTAACCT } \\
\text { CGCTGGCCG TGATCTCACA GCCTGGATGG TCAAGCTTCT CACAGAGCGTG } \\
\text { GCAATGCTT TCAACACAAC AGCCGAAAAG GAAATCGTTC GTGACATCAAG } \\
\text { GAGAAGCTT TGCTATGTCG CCCTCGACTT CGATGCTGAA ATGGAGAAGGC } \\
\text { CGCTACAGA CTCCTCCATC AACGTC }\end{array}$ \\
\hline 386 & HindII & 687 & None & 1072 & $\begin{array}{c}\text { AACTACACAC TTCCAGATGG CAACGTCATC ACAATCGGCA ATGAGCGCTTC } \\
\text { CGCTGCCCA GAAATGCTCT TCAAGCCATA CTTCGATGGT ATGGAATACGA } \\
\text { TGGTATCGA CAAGACACTC TTCGACTCCA TCATGAAGTG CGATATCGATG } \\
\text { TTCGTAAGG ATCTCTACGC TAACATCGTT CTTTCTGGTG GCACAACAATG } \\
\text { TTCCAAGGG CATCGCCGAA CGTCTTGACA AGGAAATCAC AGCTCTTGCTC } \\
\text { CACCAACAA TGAAGGTCAA GATCGTCGCC CCAGAAGAGC GTAAGTACGCC } \\
\text { GTTTGGGTC GGTGGCTCCA TCCTTGCTTC CCTCGCTACA TCCCACAGATG } \\
\text { GGTATCACA AGGAGGAATA CGACGAGGCT GGTCTC }\end{array}$ \\
\hline 200 & None & 1 & HindII & 200 & $\begin{array}{l}\text { ACGATACGCT CTGGTATGTG CAAGACGGCT TCTCTGGCGA TGAAGCCCCAC } \\
\text { GCTCTGTTT TTCCCATCCG TTGTTGGCCG ATCCAAAAGT ACAAACAACAA } \\
\text { TTAGTTGGT GGCAACGCCA AGGATGTCTT CGTCGGTGAT GAAGCTTGCTC } \\
\text { CAAGGCTGG TGTCCTCATC CTCAAGTACC CAATTGAACA CGGTATCGTC }\end{array}$ \\
\hline 60 & HindII & 201 & HindII & 260 & $\begin{array}{c}\text { AACAACTGGG ATGATATGGA AAAGATCTGG CACCACACAT TCTACAACG } \\
\text { AACTTCGTGTT }\end{array}$ \\
\hline
\end{tabular}

TABle 3: Fragment sizes obtained after digestion of the actin gene with the restriction enzymes HindII, MseI, and RsaI as well as the assignment of the T. vaginalis genotypes based on combining the patterns across the three enzyme profiles.

\begin{tabular}{|c|c|c|c|c|c|c|c|}
\hline $\begin{array}{l}\text { Sample } \\
\text { name }\end{array}$ & HindII fragment sizes & $\begin{array}{l}\text { HindII } \\
\text { pattern }\end{array}$ & $\begin{array}{l}\text { MseI fragment } \\
\text { sizes }\end{array}$ & $\begin{array}{c}\text { MseI } \\
\text { pattern }\end{array}$ & $\begin{array}{l}\text { RsaI fragment } \\
\text { sizes }\end{array}$ & $\begin{array}{c}\text { RsaI } \\
\text { pattern }\end{array}$ & Genotype \\
\hline TV4 & $60,200386,426$ & 2 & 519,581 & 1 & $106,190,236,568$ & 1 & G \\
\hline TV9 & $60,200386,426$ & 2 & 519,581 & 1 & $106,190,236,568$ & 1 & G \\
\hline TV48 & $60,200386,426$ & 2 & 519,581 & 1 & $106,190,236,568$ & 1 & G \\
\hline TV79 & $60,200386,426$ & 2 & 519,581 & 1 & $106,190,236,568$ & 1 & G \\
\hline TV95 & $60,200386,426$ & 2 & 519,581 & 1 & $106,190,236,568$ & 1 & G \\
\hline TV128 & $60,200386,426$ & 2 & 519,581 & 1 & $106,190,236,568$ & 1 & G \\
\hline TV184 & $60,200386,426$ & 2 & 519,581 & 1 & $106,190,236,568$ & 1 & G \\
\hline TV211 & $\begin{array}{c}60,80,120,200330 \\
426\end{array}$ & 2 & 519,581 & 1 & $106,190,236,452$ & 3 & I \\
\hline TV230 & $60,200,426,449$ & 2 & 519,581 & 1 & $106,190,236,568$ & 1 & G \\
\hline TV232 & $60,200399,426$ & 2 & 519,581 & 1 & $106,190,236,568$ & 1 & G \\
\hline TV253 & $60,208397,426$ & 2 & 519,581 & 1 & $106,190,236,568$ & 1 & G \\
\hline TV266" & $60,200386,426$ & 2 & $-*$ & & $106,236,568$ & 2 & $\begin{array}{c}\text { Could not be } \\
\text { assigned }\end{array}$ \\
\hline TV270 & $60,202387,426$ & 2 & 519,581 & 1 & $106,190,236,568$ & 1 & G \\
\hline TV302 & $60,200390,426$ & 2 & 519,581 & 1 & $106,190,236,568$ & 1 & G \\
\hline TV357 & $60,201387,426$ & 2 & 519,581 & 1 & $106,190,236,568$ & 1 & G \\
\hline TV358 & $60,199388,426$ & 2 & 519,581 & 1 & $106,236,568$ & 2 & $\mathrm{H}$ \\
\hline
\end{tabular}

*(-) symbol indicates that no banding pattern was observed. ${ }^{\#}$ Genotype could not be assigned due to no banding pattern for MseI.

identical banding profile was observed for all the samples. Bands at positions $519 \mathrm{bp}$ and $581 \mathrm{bp}$ were observed (Figure 4). All of the samples producing a digestion pattern were assigned the code pattern 1 (Table 3 ).
3.4. Frequency of Genotypes. According to the combined pattern codes for all three enzymes, the G genotype was the most frequent genotype in our study population. A total of $13 / 16$ $(81.25 \%)$ of the samples harboured this genotype. One 

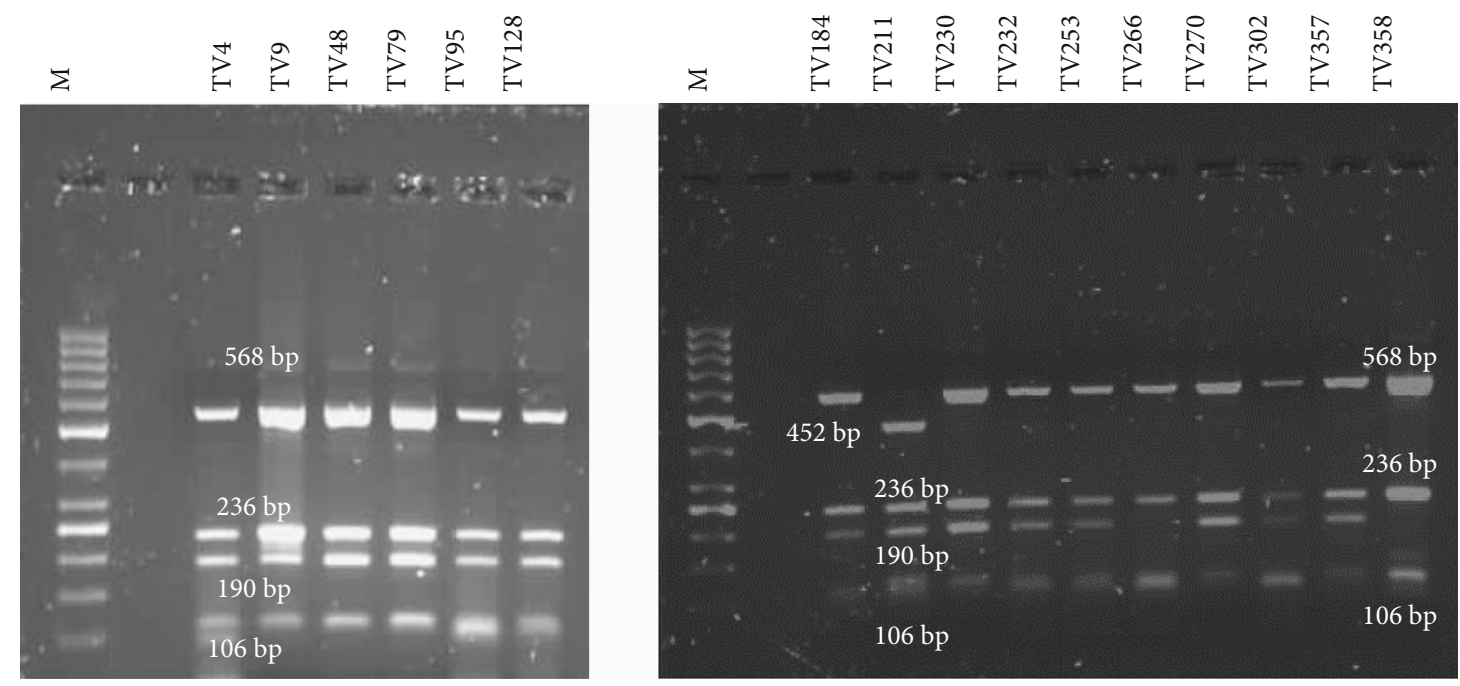

FIGURE 3: RsaI RFLP pattern of the digested actin gene amplicon resolved on a $1.5 \%$ agarose gel. O'GeneRuler $50 \mathrm{bp}$ DNA Ladder (ThermoFisher Scientific) and banding profiles of the clinical samples. Fragment sizes of $106 \mathrm{bp}, 190 \mathrm{bp}, 236 \mathrm{bp}, 452 \mathrm{bp}$, and $568 \mathrm{bp}$ were observed.

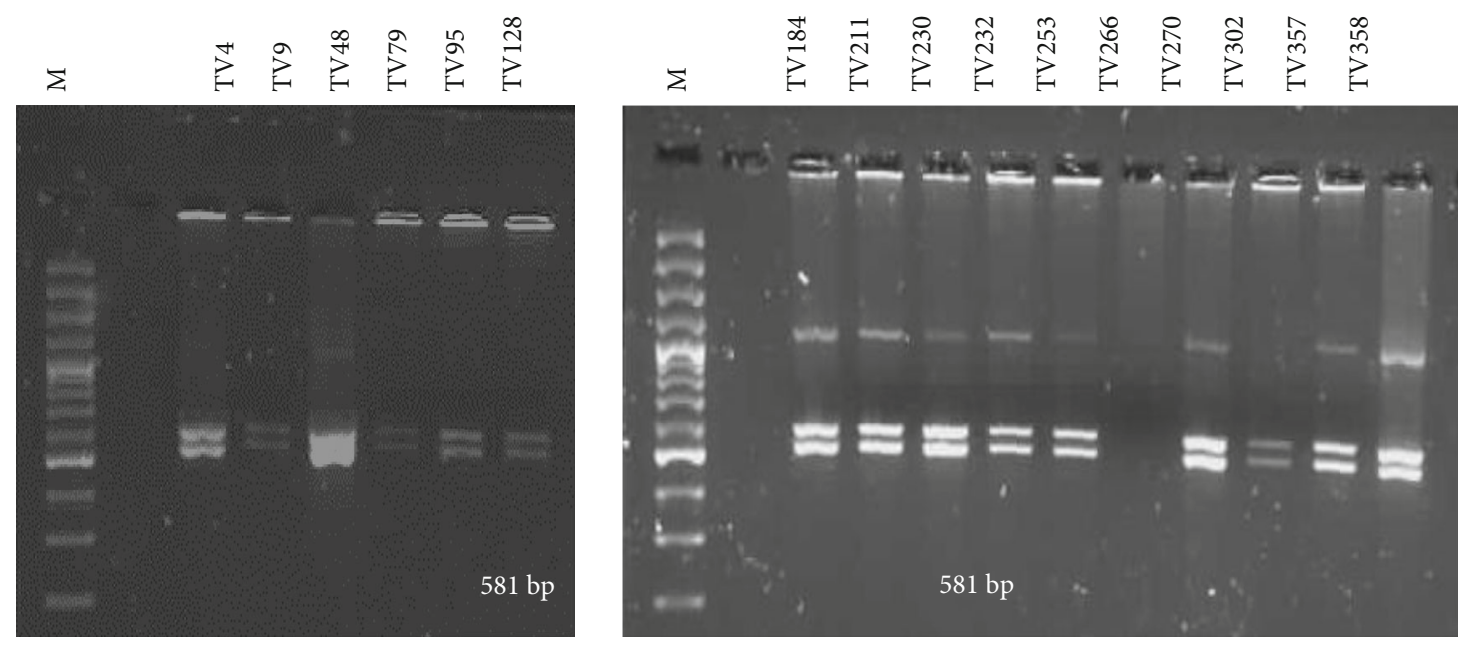

FIGURE 4: MseI RFLP pattern of the digested actin gene amplicon resolved on a 1.5\% agarose gel. M: 100 bp DNA ladder (ThermoFisher Scientific) and banding profiles of the clinical samples. Fragment sizes of $519 \mathrm{bp}$ and $581 \mathrm{bp}$ were observed.

sample (TV358) harboured genotype H (6.25\%). Similarly, one sample (TV211) harboured genotype I (6.25\%). There was one sample (TV266) that could not be assigned a genotype since it lacked a banding profile for MseI; a pattern code could therefore not be determined. This sample was therefore excluded from further sequence analysis (Table 3 ).

3.5. Phylogenetic Analysis of the Actin Gene Open Reading Frame. Translated nucleotide sequences obtained for the actin gene from selected clinical samples were edited and aligned with published sequences for genotypes $G$ and $H$. There were no published sequences for genotype I to include in this analysis. According to the multiple sequence alignment, a total of four different single-nucleotide changes in the open reading frame (ORF) of the actin gene was detected (Figure 5). Sample TV358 (genotype H) contained a single amino acid substitution from glutamine $(\mathrm{Q})$ to lysine $(\mathrm{K})$.
Sample TV184 (genotype G) contained a single amino acid subsititution from glutamic acid (E) to arginine (R). Sample TV357 (genotype G) contained two amino acid substitutions. The first change was the replacement of leucine (L) with arginine $(R)$, and the second change was the replacement of GLYCINE (G) with aspartic acid (D). The change from $\mathrm{G} \rightarrow \mathrm{D}$ was also observed for a published $T$. vaginalis ATCC genotype G strain (EU076578) (Figure 5).

The phylogenetic analysis of the actin ORF from the clinical samples and published genotypes showed the presence of distinct clusters. Overall, the majority of the samples analysed in this study were not closely related to any of the published sequences with the exception of samples TV357 and TV358 (Figure 6). The tree contained one cluster with only the clinical samples from genotype $G$ (4 samples) and the one sample from genotype I. This indicates that there was no significant diversity in the actin ORF of genotype I and 


\begin{tabular}{|c|c|}
\hline TV270 & ------HPSLSRPKYKQQLVGGNAKDVFVGDEACSKAGVLILKYPIEHGIVNNWDDMEK \\
\hline TV302 & ------HPLFSRPKYKQQLVGGNAKDVFVGDEACSKAGVLILKYPIEHGIVNNWDDMEK \\
\hline TV230 & $----------M E K$ \\
\hline TV232 & $----------M E K$ \\
\hline TV211 & 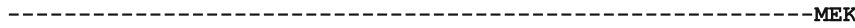 \\
\hline TV358 & ------IRLLARPKYKQQLVGGNAKDVFVGDEACSKAGVLILKYPIEHGIVNNWDDMEK \\
\hline KF747377 & EAPRSVFPSVVGRPKYKQQLVGGNAKDVFVGDEACSKAGVLILKYPIEHGIVNNWDDMEK \\
\hline EU076579 & EAPRSVFPSVVGRPKYKQQLVGGNAKDVFVGDEACSKAGVLILKYPIEHGIVNNWDDMEK \\
\hline EU076581 & EAPRSVFPSVVGRPKYKQQLVGGNAKDVFVGDEACSKAGVLILKYPIEHGIVNNWDDMEK \\
\hline EU076578 & EAPRSVFPSVVGRPKYKQQLVGGNAKDVFVGDEACSKAGVLILKYPIEHGIVNNWDDMEK \\
\hline TV357 & EAPRSVFPSVVGRPKYKQQLVGGNAKDVFVGDEACSKAGVLILKYPIEHGIVNNWDDMEK \\
\hline TV184 & 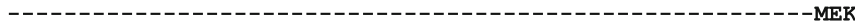 \\
\hline TV253 & - \\
\hline TV270 & IWHHTFYNELRVDPTEHPVLLTEAPLNPKANREKMI SLMFDTFNVPSFYVGIQAVLSLYS \\
\hline TV302 & IWHHTFYNELRVDPTEHPVLLTEAPLNPKANREKMISLMFDTFNVPSFYVGIQAVLSLYS \\
\hline TV230 & IWHHTFYNELRVDPTEHPVLLTEAPLNPKANREKMISLMFDTFNVPSFYVGIQAVLSLYS \\
\hline TV232 & IWHHTFYNELRVDPTEHPVLLTEAPLNPKANREKMISLMFDTFNVPSFYVGIQAVLSLYS \\
\hline TV211 & IWHHTFYNELRVDPTEHPVLLTEAPLNPKANREKMISLMFDTFNVPSFYVGIQAVLSLYS \\
\hline TV358 & IWHHTFYNELRVDPTEHPVLLTEAPLNPKANREKMISLMFDTFNVPSFYVGIQAVLSLYS \\
\hline KF747377 & IWHHTFYNELRVDPTEHPVLLTEAPLNPKANREKMISLMFDTFNVPSFYVGIQAVLSLYS \\
\hline EU076579 & IWHHTFYNELRVDPTEHPVLLTEAPLNPKANREKMISLMFDTFNVPSFYVGIQAVLSLYS \\
\hline EU076581 & IWHHTFYNELRVDPTEHPVLLTEAPLNPKANREKMISLMFDTFNVPSFYVGIQAVLSLYS \\
\hline EU076578 & IWHHTFYNELRVDPTEHPVLLTEAPLNPKANREKMISLMFDTFNVPSFYVGIQAVLSLYS \\
\hline TV357 & IWHHTFYNELRVDPTEHPVLLTEAPLNPKANREKMISLMFDTFNVPSFYVGIQAVLSLYS \\
\hline TV184 & IWHHTFYNELRVDPTEHPVLLTEAPLNPKANREKMISLMFDTFNVPSFYVGIQAVLSLYS \\
\hline TV253 & 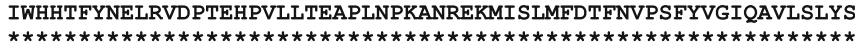 \\
\hline TV270 & SGRTTGIVFDAGDGVSHTVPIYEGYSLPHAIMRLNLAGRDLTAWMVKLLTERGNAFNTTA \\
\hline TV302 & SGRTTGIVFDAGDGVSHTVPIYEGYSLPHAIMRLNLAGRDLTAWMVKLLTERGNAFNTTA \\
\hline TV230 & SGRTTGIVFDAGDGVSHTVPIYEGYSLPHAIMRLNLAGRDLTAWMVKLLTERGNAFNTTA \\
\hline TV232 & SGRTTGIVFDAGDGVSHTVPIYEGYSLPHAIMRLNLAGRDLTAWMVKLLTERGNAFNTTA \\
\hline TV211 & SGRTTGIVFDAGDGVSHTVPIYEGYSLPHAIMRLNLAGRDLTAWMVKLLTERGNAFNTTA \\
\hline TV358 & SGRTTGIVFDAGDGVSHTVPIYEGYSLPHAIMRLNLAGRDLTAWMVKLLTERGNAFNTTA \\
\hline KF747377 & SGRTTGIVFDAGDGVSHTVPIYEGYSLPHAIMRLNLAGRDLTAWMVKLLTERGNAFNTTA \\
\hline EU076579 & SGRTTGIVFDAGDGVSHTVPIYEGYSLPHAIMRLNLAGRDLTAWMVKLLTERGNAFNTTA \\
\hline EU076581 & SGRTTGIVFDAGDGVSHTVPIYEGYSLPHAIMRLNLAGRDLTAWMVKLLTERGNAFNTTA \\
\hline EU076578 & SGRTTGIVFDAGDGVSHTVPIYEGYSLPHAIMRLNLAGRDLTAWMVKLLTERDNAFNTTA \\
\hline TV357 & SGRTTGIVFDAGDGVSHTVPIYEGYSLPHAIMRRNLAGRDLTAWMVKLLTERDNAFNTTA \\
\hline TV184 & SGRTTGIVFDAGDGVSHTVPIYEGYSLPHAIMRLNLAGRDLTAWMVKLLTERGNAFNTTA \\
\hline TV253 & 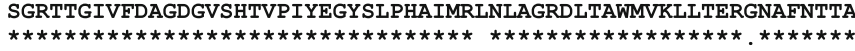 \\
\hline TV270 & EKEIVRDIKEKLCYVALDFDAEMEKAATDSS INVNYTLPDGNVITIGNERFRCPEMLFKP \\
\hline TV302 & EKEIVRDIKEKLCYVALDFDAEMEKAATDSS INVNYTLPDGNVITIGNERFRCPEMLFKP \\
\hline TV230 & EKEIVRDIKEKLCYVALDFDAEMEKAATDSSINVNYTLPDGNVITIGNERFRCPEMLFKP \\
\hline TV232 & EKEIVRDIKEKLCYVALDFDAEMEKAATDSSINVNYTLPDGNVITIGNERFRCPEMLFKP \\
\hline TV211 & EKEIVRDIKEKLCYVALDFDAEMEKAATDSSINVNYTLPDGNVITIGNERFRCPEMLFKP \\
\hline TV358 & EKEIVRDIKEKLCYVALDFDAEMEKAATDSS INVNYTLPDGNVITIGNERFRCPEMLFKP \\
\hline KF747377 & EKEIVRDIKEKLCYVALDFDAEMEKAATDSSINVNYTLPDGNVITIGNERFRCPEMLFKP \\
\hline EU076579 & EKEIVRDIKEKLCYVALDFDAEMEKAATDSSINVNYTLPDGNVITIGNERFRCPEMLFKP \\
\hline EU076581 & EKEIVRDIKEKLCYVALDFDAEMEKAATDSS INVNYTLPDGNVITIGNERFRCPEMLFKP \\
\hline EU076578 & EKEIVRDIKEKLCYVALDFDAEMEKAATDSSINVNYTLPDGNVITIGNERFRCPEMLFKP \\
\hline TV357 & EKEIVRDIKEKLCYVALDFDAEMEKAATDSSINVNYTLPDGNVITIGNERFRCPEMLFKP \\
\hline TV184 & EKEIVRDIKEKLCYVALDFDAEMEKAATDSS INVNYTLPDGNVITIGNERFRCPEMLFKP \\
\hline TV253 & 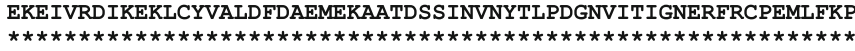 \\
\hline TV270 & YFDGMEYDGIDKTLFDSIMKCDIDVRKDLYANIVLSGGTTMFQGIAERLDKEITALAPPT \\
\hline TV302 & YFDGMEYDGIDKTLFDSIMKCDIDVRKDLYANIVLSGGTTMFQGIAERLDKEITALAPPT \\
\hline TV230 & YFDGMEYDGIDKTLFDSIMKCDIDVRKDLYANIVLSGGTTMFQGIAERLDKEITALAPPT \\
\hline TV232 & YFDGMEYDGIDKTLFDSIMKCDIDVRKDLYANIVLSGGTTMFQGIAERLDKEITALAPPT \\
\hline TV211 & YFDGMEYDGIDKTLFDSIMKCDIDVRKDLYANIVLSGGTTMFQGIAERLDKEITALAPPT \\
\hline TV358 & YFDGMEYDGIDKTLFDSIMKCDIDVRKDLYANIVLSGGTTMFKGIAERLDKEITALAPPT \\
\hline KF747377 & YFDGMEYDGIDKTLFDSIMKCDIDVRKDLYANIVLSGGTTMFQGIAERLDKEITALAPPT \\
\hline EU076579 & YFDGMEYDGIDKTLFDSIMKCDIDVRKDLYANIVLSGGTTMFQGIAERLDKEITALAPPT \\
\hline EU076581 & YFDGMEYDGIDKTLFDSIMKCDIDVRKDLYANIVLSGGTTMFQGIAERLDKE ITALAPPT \\
\hline EU076578 & YFDGMEYDGIDKTLFDSIMKCDIDVRKDLYANIVLSGGTTMFQGIAERLDKEITALAPPT \\
\hline TV357 & YFDGMEYDGIDKTLFDSIMKCDIDVRKDLYANIVLSGGTTMFQGIAERLDKEITALAPPT \\
\hline TV184 & YFDGMEYDGIDKTLFDSIMKCDIDVRKDLYANIVLSGGTTMFQGHRRTS------1 \\
\hline TV253 & YFDGMEYDGIDKTLFDSIMKCDIDVRKDLYANIVLSGGTTMFQGIAERLDKEITAI \\
\hline & \\
\hline
\end{tabular}

FIGURE 5: Multiple sequence alignment of the actin ORF from clinical samples and published genotypes using ClustalW (GenomeNet). A total of 4 different single-nucleotide changes in the open reading frame (ORF) of the actin gene were detected for the clinical samples (changes highlighted in yellow). A single change in one of the published sequences was also noted (highlighted in green).

certain genotype $\mathrm{G}$ samples. However, within the group of genotype G samples, a level of diversity was noted. Samples TV184, TV253, and TV357 did not cluster with the other genotype G samples. TV184 contained a single amino acid substitution $(\mathrm{E} \rightarrow \mathrm{R})$ which was not present in the other genotype G samples. Sample TV253 did not contain any substitutions; however, it did not cluster with the other samples of genotype $\mathrm{G}$ without substitutions. Sample TV357 was shown 


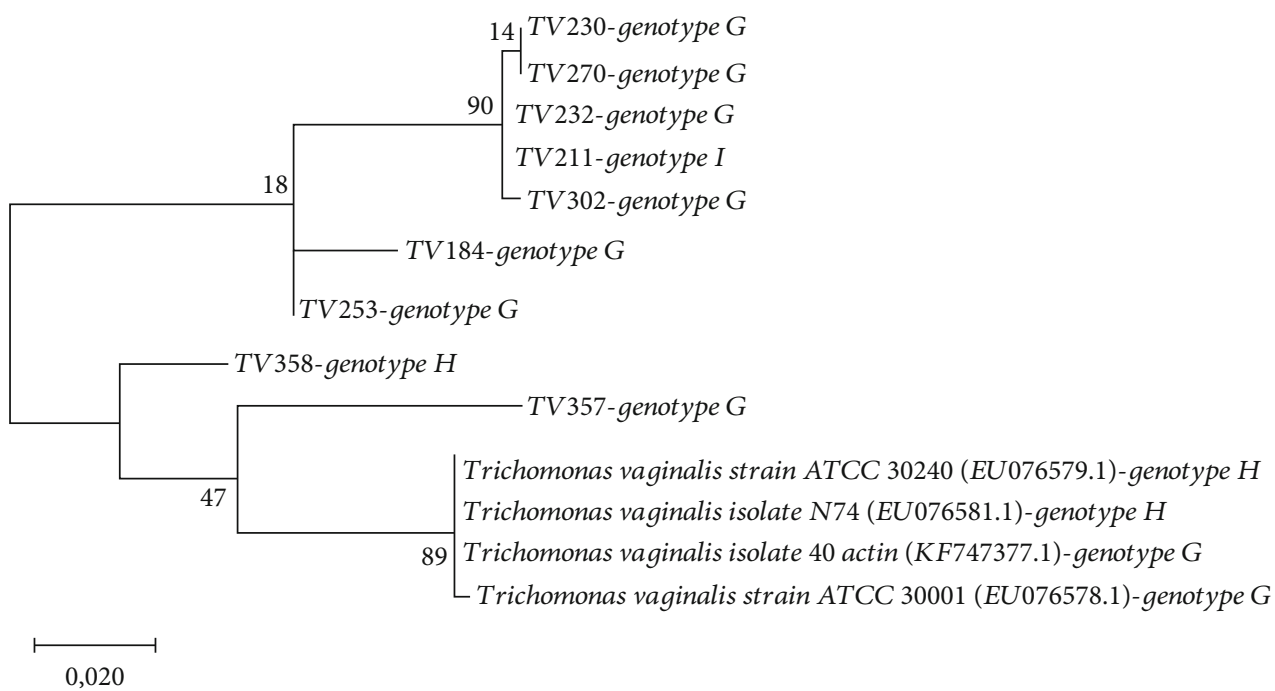

FIGURE 6: Phylogenetic tree analysis of Trichomonas vaginalis actin genotypes according to the maximum-likelihood (ML) tree was conducted based on the multiple sequence alignment of actin gene by MEGA V10. Distance represents the number of base substitutions per site.

TABLE 4: Genotypes linked to clinical symptoms of infection.

\begin{tabular}{lcc}
\hline Genotype & Number of isolates $(\%)$ & Clinical symptoms reported \\
\hline $\mathrm{I}$ & $1 / 1(100 \%)$ & Abnormal vaginal discharged, foul-smelling vaginal odour, genital itching, and genital warts \\
$\mathrm{H}$ & $1 / 1(100 \%)$ & No symptoms \\
$\mathrm{G}$ & $7 / 13(53.85 \%)$ & No symptoms \\
$\mathrm{G}$ & $3 / 13(23.08 \%)$ & Abnormal vaginal discharged \\
$\mathrm{G}$ & $2 / 13(15.38 \%)$ & Genital itching \\
$\mathrm{G}$ & $1 / 13(7.69 \%)$ & Abnormal vaginal discharged and genital itching \\
\hline
\end{tabular}

to cluster closely to the published $\mathrm{G}$ and $\mathrm{H}$ genotypes. This sample also carried two amino acid substitutions in the actin gene ORF $(\mathrm{L} \rightarrow \mathrm{R})$ and $(\mathrm{G} \rightarrow \mathrm{D})$. One of these substitutions $(\mathrm{G} \rightarrow \mathrm{D})$ was also observed for one of the published genotype G strains (EU076578). Sample TV358 (genotype H) clustered on its own. This sample also contained a substitution $(\mathrm{Q} \rightarrow \mathrm{K})$ in the actin gene ORF (Figure 5).

3.6. Distribution of Genotypes in Relation to Clinical Symptoms. Overall, the median age of the women who tested positive for $T$. vaginalis in this study was 28.0 (24.0-32.5). The majority of the study women had completed high school $(68.1 \%)$, were unmarried $(91.5 \%)$, had a regular sex partner (80.9\%), had between 2 and 4 lifetime sex partners $(66.0 \%)$, and were in the last trimester of pregnancy (59.6\%) (data not shown).

For the one woman who carried genotype I, it was shown that this woman reported multiple symptoms associated with STIs such as abnormal vaginal discharge, foul-smelling vaginal odour, genital itching, and genital warts (Table 4). The one woman harboured genotype $\mathrm{H}$ was asymptomatic (Table 4). For the women who harboured genotype G, it was shown that a large proportion of these women $(53.8 \%)$ were asymptomatic, followed by $23.0 \%$ who reported symptoms of abnormal vaginal discharge, $15.3 \%$ who reported genital itching, and $7.6 \%$ who reported a combination of symptoms (abnormal vaginal discharge and genital itching (Table 4).

\section{Discussion}

Trichomoniasis is considered to be the most prevalent nonviral sexually transmitted infection (STI) worldwide affecting individuals of all ages, ethnicity, and socioeconomic groups $[2,3]$. The global prevalence rates for $T$. vaginalis varies between $0.9 \%$ and $80 \%$ [14-16].

In this study, the prevalence of $T$. vaginalis in antenatal women was approximately $13.0 \%$. The risk factors associated with infection in this cohort which have been described elsewhere included previous history of STIs and current abnormal vaginal discharge [17]. A similar prevalence rate of $10 \%$ for T. vaginalis was observed for antenatal women from Durban [18]. The prevalence estimates reported in South African women correlate with the rates reported for other African countries. A study conducted by AbouKamar et al. [16] in Egypt on pregnant and nonpregnant women showed a prevalence rate of $13.5 \%$ for $T$. vaginalis. An earlier study conducted by the WHO in the African region in women aged 15 to 49 years of age reported an estimated prevalence rate of $11.5 \%$ for $T$. vaginalis infection [19]. 
Early techniques which were applied for the typing of $T$. vaginalis isolates included; antigenic characterisation [20], monoclonal antibody binding [21], karyotype polymorphism by pulsed-field gel electrophoresis [22] [23], random amplified polymorphic DNA (RAPD) [24], and restriction fragment length polymorphisms (RFLP) [25]. Despite the numerous list of typing techniques, each of the abovementioned had significant limitations [11].

Currently, the PCR-RFLP technique based on the actin gene amplification provides a sensitive and reliable method for typing of T. vaginalis isolates [26]. In this study, three different genotypes of $T$. vaginalis were identified by PCR-RFLP of the actin gene. The most frequent genotype in our study population was the genotype $\mathrm{G}$. Other $T$. vaginalis genetic studies conducted on the African continent revealed the presence of genotypes $\mathrm{G}$ and $\mathrm{E}$ as highly prevalent [12] [27],. A study conducted in the Democratic Republic of Congo (DRC) and Zambia on female sex workers revealed the presence of eight different genotypes based on the actin gene. In the DRC, the most prevalent genotype was E, whereas in Zambia the most common genotype was $G$ [12]. Our study findings are consistent with the findings from Zambia. A study conducted on pregnant women from Kenya reported a high frequency of genotype E [27] which is similar to the results obtained for the DRC [12]. From the abovementioned studies, it is evident that common genotypes of T. vaginalis are circulating in various population groups across the African continent. In a study conducted in Ndola, Zambia, involving adolescent girls and pregnant women as well as sex workers, Crucitti et al. [28] identified nine different genotypes, with genotype $G$ being the most frequent across all three study groups. This is similar to the findings of the pregnant women tested in the current study.

In studies conducted out of Africa, Momeni et al. [29] identified five different genotypes with genotype $G$ being the most prevalent in a population of Iranian men and women. However, three recent studies conducted in Iran [6] [26], [30], observed a high prevalence of $T$. vaginalis genotypes which differed from the genotypes observed in Africa and those reported by Momeni et al. [29] for Iran. Matini et al. [30] investigated the prevalence of T. vaginalis genotypes in symptomatic and asymptomatic women, attending gynaecology clinics in western Iran. According to the actin gene digestion profiles, genotype $\mathrm{A}$ was shown to be the most prevalent in their study population [30]. A study conducted on women seeking care in a general clinic in southwestern Iran reported on genotype $\mathrm{H}$ as being the most frequent [6]. Similar findings were reported by Oliaee et al. 2017 [26] in a population of incarcerated women from southern Iran where genotype $\mathrm{H}$ was shown to be the most frequent [26].

In this study, within the samples that belonged to genotype $G$, a level of diversity was noted as evidenced by the multiple sequence alignments and phylogenetic analyses. Three samples TV184, TV253, and TV357 did not cluster with the other genotype $\mathrm{G}$ samples. The possibility of obtaining different genotypes involving $T$. vaginalis within a study population could be due to large sample numbers as well as obtaining samples from regions which have a much higher prevalence rate [16]. In this study, the prevalence of T. vaginalis was close to $13 \%$ and this relatively high prevalence could have contributed to the observed diversity. In addition, for the women who carried genotype $G$, it was shown that a large proportion of these women (53.8\%) were asymptomatic, followed by $23.0 \%$ who reported symptoms of abnormal vaginal discharge, $15.3 \%$ who reported genital itching, and $7.6 \%$ who reported a combination of symptoms (abnormal vaginal discharge and genital itching). A study conducted by Khalili et al. [6] also showed that in the group of women who carried genotype $G$, there was a combination of women who were asymptomatic as well as symptomatic. It is possible that the genetic differences in the pathogen may contribute to the clinical manifestations associated with infection. However, this will need to be confirmed by further investigations.

Within the genotype $G$ study samples, two of the three samples carried amino acid substitutions in the actin gene ORF. One particular sample TV357 showed a replacement of leucine (L) with arginine (R) and replacement of glycine (G) with aspartic acid (D). Similar findings were reported by Spotin et al. [31] for a T. vaginalis isolate from Iran. The multiple alignment of the Iranian isolate which was assigned genotype $\mathrm{G}$ showed amino acid substitutions where aspartic acid (D) replaced glycine (G) and arginine (R) replaced leucine $(\mathrm{L})$ [31]. This indicates that there may be a small level of similarity between $T$. vaginalis genotype $\mathrm{G}$ samples from different regions. Identifying isolates from different geographical regions which are closely related is beneficial to future vaccine development studies for this pathogen.

\section{Limitations}

In this study, the actin gene was not shown to be present in all the swab samples which tested $T$. vaginalis positive by the TaqMan assay. Other T. vaginalis genotyping studies which have been based on the actin gene were conducted on pure isolates rather than the primary vaginal swab sample. The use of the primary sample to infer genotypes may not be the most appropriate method as evidenced by the lack of amplification of certain samples. An alternate method which may be more useful for investigating the genetic variation in T. vaginalis from noncultured vaginal swabs would be the next generation-multilocus sequence typing (NG-MLST) approach described by Squire et al. [32]. However, due to budget constraints, the NG-MLST method was not used in the present study.

\section{Conclusion}

The present study provides evidence on the genetic diversity of $T$. vaginalis from a South African pregnant population. Three different genotypes were observed in the studied population. Within the genotype $\mathrm{G}$ samples, diversity in the actin gene ORF was observed. The observed diversity within specific populations can be challenging for future vaccine design and development of antigen-based rapid diagnostic tests for trichomoniasis. However, one of our South African isolates was closely related to an Iranian isolate. This holds some promise that there may be conserved $T$. vaginalis isolates 
from different geographical regions. This could lend some hope for future vaccine design and diagnostic studies focused on identifying antigenic determinants which are broadly representative of the entire $T$. vaginalis population [11].

Future work emanating from this study would be to investigate the association of the genotypes with patterns of drug susceptibility in this pathogen. In addition, it would be useful to compare the distribution of the genotypes in pregnant and nonpregnant populations as well as look at the association of the genotypes with the prevalence of the different T. vaginalis viruses (TVVs).

\section{Data Availability}

The data used to support the findings of this study are available from the corresponding author upon request.

\section{Disclosure}

The views expressed in the submitted article are those of the authors and not an official position of the institution or funder.

\section{Conflicts of Interest}

The authors declare that they have no financial or personal relationship(s) that may have inappropriately influenced them in writing this article.

\section{Acknowledgments}

We gratefully acknowledge the women from the King Edward VIII Hospital antenatal clinic who participated in this study. This study was supported by a research grant awarded to NA by the National Research Foundation (Grant number: 112080) and a SeedIT award made to SN by Inqaba Biotec.

\section{References}

[1] M. D. Conrad, A. W. Gorman, J. A. Schillinger et al., "Extensive genetic diversity, unique population structure and evidence of genetic exchange in the sexually transmitted parasite Trichomonas vaginalis," PLoS Neglected Tropical Diseases, vol. 6, no. 3, article e1573, 2012.

[2] S. N. Mavedzenge, B. Van Der Pol, H. Cheng et al., "Epidemiological synergy of Trichomonas vaginalis and HIV in Zimbabwean and South African Women," Sexually Transmitted Diseases, vol. 37, no. 7, pp. 460-466, 2010.

[3] T. Apalata, W. H. Carr, W. A. Sturm, B. Longo-Mbenza, and P. Moodley, "Determinants of symptomatic vulvovaginal candidiasis among human immunodeficiency virus type 1 infected women in rural Kwazulu-Natal, South Africa," Infectious Diseases in Obstetrics and Gynecology, vol. 2014, Article ID 387070, 10 pages, 2014.

[4] S. Naidoo, H. Wand, N. Abbai, and G. Ramjee, "High prevalence and incidence of sexually transmitted infections among women living in Kwazulu-Natal, South Africa," AIDS Research and Therapy, vol. 11, no. 1, p. 31, 2014.

[5] M. Simon, Trichomonas vaginalis infection among pregnant women in Kilifi KP, risk factors, genotyping, and interaction with the vaginal microbiome and HIV Ph.D Dissertation, Ghent University, Belgium, 2018.

[6] B. Khalili, P. Ghasemi-Dehkordi, G. Pourshahbazi, H. YousofiDarani, M. Hashemzadeh-Chaleshtori, and A. Doosti, "Genotyping of Trichomonas vaginalis isolates from women in Shahrekord city (Southwestern Iran)," Genetika, vol. 49, no. 3, pp. 1059-1070, 2017.

[7] G. Ramjee, N. S. Abbai, and S. Naidoo, "Women and Sexually Transmitted Infections in Africa," Open Journal of Obstetrics and Gynecology, vol. 5, no. 7, pp. 385-399, 2015.

[8] E. Salakos, D. Korb, C. Morin, and O. Sibony, "A case of nontreated Trichomonas vaginalis infection and severe preterm labor with positive obstetrical outcome," Journal of Gynecology Obstetrics and Human Reproduction, vol. 47, no. 4, pp. 171$173,2018$.

[9] M. F. Cotch, J. G. Pastorek, R. P. Nugent et al., "Trichomonas vaginalis Associated With Low Birth Weight and Preterm Delivery," Sexually Transmitted Diseases, vol. 24, no. 6, pp. 353-360, 1997.

[10] M. Kock, I. Rukasha, A. Dijkmans, and A. Hoosen, "P3-S7.07 detection of Trichomonas vaginalis in HIV positive women in Pretoria, South Africa," Sexually Transmitted InfectionsSex Transm Infections, vol. 87, Supplement 1, p. A301, 2011.

[11] J. C. Meade and J. M. Carlton, "Genetic diversity in Trichomonas vaginalis," Sexually Transmitted Infections, vol. 89, no. 6, pp. 444-448, 2013.

[12] T. Crucitti, S. Abdellati, E. Van Dyck, and A. Buvé, "Molecular typing of the actin gene of_Trichomonas vaginalis_isolates by PCR -restriction fragment length polymorphism," Clinical Microbiology and Infection, vol. 14, no. 9, pp. 844-852, 2008.

[13] N. Espinosa, R. Hernández, L. López-Griego, R. Arroyo, and I. López-Villaseñor, "Differences between coding and noncoding regions in the Trichomonas vaginalis genome: an actin gene as a locus model," Acta Tropica, vol. 78, no. 2, pp. 147154, 2001.

[14] Z. Valadkhani, F. Kazemi, N. Hassan, Z. Aghighi, I. Esmaili, and M. Talebi, "Gene diversity of Trichomonas vaginalis isolates," Iranian Journal of Parasitology, vol. 6, no. 3, pp. 101-106, 2011.

[15] M. Javanbakht, A. Stirland, S. Stahlman et al., "Prevalence and factors associated with Trichomonas vaginalis infection among high-risk women in Los Angeles," Sexually Transmitted Diseases, vol. 40, no. 10, pp. 804-807, 2013.

[16] W. A. Abou-kamar, A. A. Abdel-Mageid, H. A. El-Nahas, R. A. Atia, and N. L. El-Tantawy, "Genetic Relatedness of Trichomonas vaginalis Isolates to the Clinical Variability," Journal of Molecular Microbiology, vol. 1, no. 1, p. 103, 2017.

[17] N. Mabaso, C. Naicker, M. Nyirenda, and N. Abbai, "Prevalence and risk factors for Trichomonas vaginalis infection in pregnant women in South Africa," International Journal of STD \& AIDS, vol. 31, no. 4, pp. 351-358, 2020.

[18] F. Dessai, M. Nyirenda, M. Sebitloane, and N. Abbai, "Diagnostic evaluation of the BD Affirm VPIII assay as a point-ofcare test for the diagnosis of bacterial vaginosis, trichomoniasis and candidiasis," International Journal of STD \& AIDS, vol. 31, no. 4, pp. 303-311, 2020.

[19] L. Newman, J. Rowley, S. Vander Hoorn et al., "Global estimates of the prevalence and incidence of four curable sexually transmitted infections in 2012 based on systematic review and global reporting," PLoS One, vol. 10, no. 12, article e0143304, 2015. 
[20] B. E. Torian, R. J. Connelly, R. C. Barnes, and G. E. Kenny, "Antigenic Heterogeneity in the 115,000 MrMajor Surface Antigen ofTrichomonas vaginalis1," The Journal of Protozoology, vol. 35, no. 2, pp. 273-280, 1988.

[21] J. N. Krieger, K. K. Holmes, M. R. Spence, M. F. Rein, W. M. McCormack, and M. R. Tam, "Geographic variation among isolates of Trichomonas vaginalis: demonstration of antigenic heterogeneity by using monoclonal antibodies and the indirect immunofluorescence technique," Journal of Infectious Diseases, vol. 152, no. 5, pp. 979-984, 1985.

[22] J.-S. Ryu, D.-Y. Min, M.-H. Shin, and Y. H. Cho, "Genetic variance of Trichomonas vaginalis isolates by Southern hybridization," The Korean Journal of Parasitology, vol. 36, no. 3, pp. 207-211, 1998.

[23] J. A. Upcroft, M. G. Delgadillo-Correa, R. L. Dunne, A. W. Sturm, P. J. Johnson, and P. Upcroft, "Genotyping Trichomonas vaginalis," International Journal for Parasitology, vol. 36, no. 7, pp. 821-828, 2006.

[24] P. Kaul, I. Gupta, R. Sehgal, and N. Malla, "Trichomonas vaginalis: random amplified polymorphic DNA analysis of isolates from symptomatic and asymptomatic women in India," Parasitology International, vol. 53, no. 3, pp. 255-262, 2004.

[25] J. C. Meade, J. de Mestral, J. K. Stiles et al., "Genetic diversity of Trichomonas vaginalis clinical isolates determined by EcoRI restriction fragment length polymorphism of heat-shock protein 70 genes," The American Journal of Tropical Medicine and Hygiene, vol. 80, no. 2, pp. 245-251, 2009.

[26] R. Tavakoli Oliaee, Z. Babaei, G. R. Hatam et al., "Considerable genetic diversity of Trichomonas vaginalis clinical isolates in a targeted population in South of Iran," Iranian Journal of Parasitology, vol. 12, no. 2, pp. 251-259, 2017.

[27] S. C. Masha, P. Cools, T. Crucitti, E. J. Sanders, and M. Vaneechoutte, "Molecular typing of Trichomonas vaginalis isolates by actin gene sequence analysis and carriage of T. vaginalis viruses," Parasites \& Vectors, vol. 10, no. 1, p. 537, 2017.

[28] T. Crucitti, V. Jespers, C. Mulenga, S. Khondowe, J. Vandepitte, and A. Buvé, "Trichomonas vaginalis is highly prevalent in adolescent girls, pregnant women, and commercial sex workers in Ndola, Zambia," Sexually Transmitted Diseases, vol. 37, no. 4, pp. 223-227, 2009.

[29] Z. Momeni, J. Sadraei, B. Kazemi, and A. Dalimi, "Molecular typing of the actin gene of Trichomonas vaginalis isolates by PCR-RFLP in Iran," Experimental Parasitology, vol. 159, pp. 259-263, 2015.

[30] M. Matini, M. Rezaeian, M. Mohebali et al., "Genotyping of Trichomonas vaginalis isolates in Iran by using single stranded conformational polymorphism-PCR technique and internal transcribed spacer regions," Tropical Biomedicine, vol. 29, no. 4, pp. 605-612, 2012.

[31] A. Spotin, S. T. Eghtedar, A. Shahbazi et al., "Molecular characterization of Trichomonas vaginalis strains based on identifying their probable variations in asymptomatic patients," Iranian Journal of Parasitology, vol. 11, no. 4, pp. 507-514, 2016.

[32] D. S. Squire, A. J. Lymbery, J. Walters, F. Brigg, A. Paparini, and R. C. A. Thompson, "Population structure and genetic diversity of Trichomonas vaginalis clinical isolates in Australia and Ghana," Infection, Genetics and Evolution, vol. 82, article 104318, 2020. 